\title{
LA SOLIDEZ DEL CRISTAL: LA IMPORTANCIA DEL TIEMPO PARA EXPLICAR LA CALIDAD DE LAS LEYES DE ACCESO A LA INFORMACIÓN
}

\author{
Grisel Salazar Rebolledo
}

\section{INTRODUCGIÓN}

En septiembre de 2014, con la aprobación de la Ley de Libre Acceso Ciudadano a la Información Pública y Transparencia Gubernamental paraguaya, sumaron exactamente cien leyes de acceso a la información (LAI) existentes en el mundo. Pocos son los países que no han regulado este ámbito, y menos aún las democracias que no han expedido una legislación específica en la materia.

El repunte de las LAI vino aparejado, precisamente, a la última ola de transiciones a la democracia. Hasta 1995, la totalidad de las leyes existentes pertenecían a países desarrollados; en la siguiente década, la mitad de las leyes aprobadas provino de Europa del Este y Europa Central, y la otra mitad de América Latina y Asia, regiones caracterizadas por el desmantelamiento de un buen número de regímenes autoritarios iniciado en la década de $1990{ }^{1}$ Poco a poco, el derecho de acceso a la información ganó terreno como una de las condiciones irrenunciables que debía incluir una democracia liberal de manera explícita, ${ }^{2}$ y se volvió una exigencia reconocida por los Estados que pretendían transitar desde un

${ }^{1}$ Mendel, RTI Rating Data Analysis Series: Overview of Results and Trends, CanadáEspaña, CLD-AIE, 2013.

${ }^{2}$ A pesar de que la transparencia y la publicidad son dos ideas ligadas a la tradición liberal, presentes en el pensamiento de Kant o Bentham, lo cierto es que siempre estuvieron subsumidas a otros derechos (como el derecho de expresión o de libertad de prensa). Sólo hasta mediados del siglo xx pasan de estar en el telón 
régimen autoritario a una democracia. El contagio regional, las recomendaciones de los organismos internacionales, las crecientes demandas ciudadanas y la rentabilidad política de la transparencia son factores que explican la proliferación de las LAI en las últimas décadas.

Aunque la transparencia y el acceso a la información son temas que han ganado un creciente interés social, mediático y académico, pocos estudios han abordado de manera sistemática las diferencias en la calidad de las LAI, y más bien se han concentrado en las razones que han impulsado su aprobación, sin detenerse a considerar las diferencias entre ellas. Sin embargo, existe un amplio abanico de configuraciones institucionales de transparencia ${ }^{3}$ y, por supuesto, una enorme dispersión en la calidad de las leyes aprobadas, lo que afecta su capacidad para convertirse en una herramienta efectiva.

La explicación sobre la calidad de estos instrumentos es una tarea pendiente, no sólo por su expansión a gran escala, sino por las implicaciones que guardan para los equilibrios de poder: su potencial para restringir las áreas de arbitrariedad de las ramas de gobierno (especialmente de la Ejecutiva), y para alimentar la toma de decisiones de los votantes supone un giro para el control del poder público. Detonar este potencial depende de manera sustantiva-aunque no exclusiva- de una configuración normativa sólida y de calidad.

¿Cómo explicamos, entonces, el nivel de calidad de las LAI? Una de las primeras explicaciones que aparece de modo casi espontáneo es la calidad de la democracia: la relación entre transparencia y democracia se antoja casi simbiótica, y parece natural que las LAI más antiguas hayan aparecido en democracias de larga data. Sin embargo, una mirada más cuidadosa al diverso panorama de las LAI existentes arroja algunas incógnitas interesantes. Una de las evaluaciones más comprehensivas de la calidad de las

de fondo a ocupar un lugar central y explícito en las premisas que sustentan todo régimen democrático, que merece una regulación específica.

3 Neuman, Enforcement Models: Content and Context, Washington, World Bank, 2009. 
LAI existentes, el Right to Information Rating, muestra que las democracias más consolidadas aparecen dentro de los últimos veinte sitios, mientras que los primeros lugares están ocupados por democracias jóvenes, o bien por países en plena transición. Otras explicaciones como la capacidad burocrática o el nivel socioeconómico tampoco arrojan explicaciones satisfactorias. ${ }^{4}$ Esta incógnita amerita una explicación.

El objetivo de este texto es explorar diversas respuestas a esta variación. Las primeras explicaciones están basadas en indicadores típicos, tales como la calidad de la democracia y el grado de libertades existentes en un país en determinado momento. El segundo grupo de explicaciones busca avanzar una respuesta basada en variables temporales.

El tiempo, como se ha argumentado, ${ }^{5}$ constituye una variable de suma relevancia que condiciona los estándares bajo los cuales se configura una política pública; los trazos del tiempo son, si no indelebles, sí lo suficientemente profundos como afectar diseños institucionales, por muy novedosos que se presenten.

Para este trabajo, se considera que las trayectorias temporales a las LAI influyen en dos sentidos: en primer lugar, se propone que la calidad de las LAI es producto de un aprendizaje de leyes previas y de las exigencias ciudadanas, que se vuelven más demandantes conforme se revelan las limitaciones de las primeras experiencias; en ese sentido, las leyes más jóvenes tenderán a incorporar elementos más robustos que las más antiguas, y su calidad será más alta. En segundo lugar, se considera que países en tránsito a la democracia, con largas tradiciones de opacidad administrativa, ven en una LAI robusta, no sólo un instrumento de rentabilidad política y botón de muestra con el compromiso democrático, sino una herramienta para sobreponerse a la persistencia de la "cultura del secreto", en términos formales.

${ }^{4}$ Michener, "FOI Laws Around the World", Journal of Democracy, vol. 22, núm. 2, 2011, pp. 145-159.

5 Andreas Schedler y Javier Santiso, "Democracy and Time: An Invitation", International Political Science Review, vol. 19, núm. 1, 1998, pp. 5-18; P. Pierson, Politics in Time, Nueva York, Cambridge University Press, 2004; C. Pollitt, Time, Policy, Management: Governing with the Past, Oxford, Oxford University Press, 2008. 
La estructura de este trabajo es la siguiente: la primera sección está dedicada a hacer un breve repaso por la proliferación de las LAI y los instrumentos que han buscado medir su calidad; se describen brevemente algunos estudios que se han realizado en torno a este tema, incluyendo el RTI Ranking, se analizan los criterios de medición de calidad de éste y los resultados que arrojó en su última edición. En la segunda sección se inicia la exploración sobre los factores que condicionan la calidad de las LAI; utilizando herramientas estadísticas, se presenta evidencia para demostrar la insuficiencia de los factores estáticos para construir una explicación satisfactoria. En la tercera parte se introduce el tiempo como variable explicativa, como recurso de aprendizaje y como condicionante de las políticas públicas. Y en la cuarta parte se ofrecen conclusiones y futuras líneas de investigación. Es necesario mencionar que las ambiciones de este trabajo son meramente exploratorias: se busca evaluar la pertinencia de incluir un tipo de variables poco exploradas para explicar la calidad de las LAI. Se adopta una mirada macroscópica, que incluye todo el universo de LAI que existen a la fecha, y no se pretende explicar las particularidades propias de leyes concretas, lo que ameritaría estudios de caso a profundidad.

\section{Calibrando la lente: la VARiedad de las leyes DE ACGESO MODERNAS}

Es posible decir que la concepción de la transparencia y el acceso a la información como prerrogativas ciudadanas corresponden a una visión moderna de estos términos. La primera normatividad que se suele aludir como referente es el "Ordenamiento relacionado con libertad de expresión y de prensa" de Suecia, promulgado en 1766; sin embargo, como su nombre lo indica, ésta era un instrumento eminentemente relacionado al quehacer de la prensa y a la abolición de la censura, que no concebía el acceso a la información como una demanda de la ciudadanía in extenso. De manera similar, la creación de la ley estadounidense, Freedom of Information Act, estuvo impulsada originalmente por las demandas puntuales de un grupo específico (la oposición) bajo el contexto de la Guerra 
Fría. ${ }^{6}$ En sus inicios, el acceso a la información no se concebía como un derecho extensivo a toda la ciudadanía, ni como un elemento ligado a un régimen democrático, sino como un instrumento para ejercer de manera más sencilla alguna labor (las tareas periodísticas o el control parlamentario, por ejemplo).

Roberts y Michener identifican 1999 como el año de la "explosión de la transparencia". ${ }^{7}$ Antes de 1990, sólo existían doce regulaciones especializadas; y es a partir de la década de 1990 cuando la aprobación de leyes de acceso a la información se registra en cascada: un gran número de países se encontraba saliendo de un régimen autoritario y, con ello, reconfigurando su entramado institucional y sus fuerzas sociales. Siguiendo a Roberts, ${ }^{8}$ es posible identificar dos trayectorias de difusión de políticas en pro de la transparencia: el impulso de organizaciones sociales que exigen la protección del acceso a la información como un derecho básico, por un lado; y por el otro, la influencia de organismos internacionales, que establecen la transparencia como requisito para el intercambio comercial, la liberalización económica y la certidumbre de los mercados. ${ }^{9}$

Paralelamente al caudal de leyes promulgadas en torno a la transparencia, empezaron a surgir los estudios que documentaban estas experiencias. Estos textos generalmente provenían de la misma comunidad de activistas que habían acompañado la aprobación de la LAI, y en su mayoría se trataban de estudios de caso. ${ }^{10}$

${ }^{6}$ M. Schudson, "Origins of the Freedom of Information Act in the United States”, en N. Bowles et al. (eds.), Transparency in Politics and the Media: Accountability and Open Government, Oxford, I.B. Tauris - Reuters Institute for the Study of Journalism, University of Oxford, 2014.

${ }^{7}$ A. Roberts, "Three Patterns in the Diffusion of Transparency Rules: Money, Guns and Human Rights”, 2003, disponible en http:/ / papers.ssrn.com/sol3/papers.cfm?abstract_id=1439722, con acceso el 20 de noviembre de 2014. También: G. Michener, “The Surrender of Secrecy”, tesis doctoral, Austin, University of Texas at Austin, 2010.

${ }^{8}$ Roberts, art. cit.

${ }^{9}$ Roberts distingue un tercer flujo de "contra difusión", que se refiere al de las políticas hostiles a la transparencia, motivadas, en gran medida, por temas de seguridad nacional.

${ }^{10}$ Para México, véase, por ejemplo, Villanueva, Derecho de acceso a la información pública en Latinoamérica, México, IIJ-Unam, 2003; Escobedo, "Movilización de 
Los primeros estudios comparados tenían más una finalidad ilustrativa, ${ }^{11} \mathrm{o}$ bien se preguntaban por las razones que habían posibilitado la aprobación de estas normas en distintos entornos. ${ }^{12}$ Estos trabajos destacaron particularmente la importancia de los procesos de democratización, de la presencia de grupos ciudadanos activos, de la voluntad política y de las presiones internacionales como factores detrás de la aprobación de las LAI. La preocupación por los distintos grados de calidad de la norma aún no se transmitía de manera explícita, aunque se habían realizado esfuerzos por contrastar diversos instrumentos normativos dentro de los países. ${ }^{13}$

Uno de los primeros estudios que abordó las diferencias en la calidad de las LAI entre países fue el análisis del Open Society Institute (osi) en 2006. Esta organización, cuyos orígenes están ligados a la caída del bloque comunista, estudió las condiciones de acceso en catorce países, siete con LAI y siete sin ella; encontró que aunque las LAI mejoraban ligeramente las condiciones de transparencia, aún en los países que contaban con ellas existían obstáculos importantes al acceso (sólo $36 \%$ de las solicitudes fueron respondidas de manera insatisfactoria), lo que indicaba que no bastaba con tener un instrumento aprobado, sino que existían diferencias

opinión pública en México: el caso del Grupo Oaxaca y la Ley Federal de Acceso a la Información Pública”, Derecho Comparado de la Información, núm. 2, 2003, pp. 63-92; López Ayllón, "La creación de la Ley de Acceso a la Información en México: una perspectiva desde el Ejecutivo Federal”, en Hugo Concha et al. (coords.), Transparentar al Estado: la experiencia mexicana de acceso a la información, México, UNAM, 2005, pp. 1-38.

${ }^{11}$ Banisar, "Freedom of Information and Access to Government Record Laws around the World"; Banisar, "Freedom of Information around the World 2006..."; Ackerman y Sandoval, "The Global Explosion of Freedom of Information Laws", Administrative Law Review, vol. 58, núm. 1, 2006, pp. 85-130. Villanueva, Derecho de acceso a la información pública en Latinoamérica; Neuman, op. cit.

12 Roberts, art. cit.; Neuman y Calland, "Making the Law Work: The Challenges of Implementation", en A. Florini (ed.), The Right to Know, Nueva York, Columbia University Press, 2007, pp. 179-213.

13 Para México, véase: Villanueva, Gómez y Pacheco, Derecho de acceso a la información pública en México: indicadores legales, México, Limac, 2005; Guerrero y Ramírez de Alba, "La transparencia en México en el ámbito subnacional: Una evaluación comparada de las leyes estatales”, en S. López Ayllón (ed.), Democracia, transparencia y constitución, México, UNAM-IFAI, 2006. 
importantes en la configuración normativa que permitían (o impedían) un procesamiento fluido de las demandas de información. En pocas palabras, este estudio llamó la atención sobre un aspecto poco analizado hasta ese momento: la varianza en la calidad de las normas aprobadas hasta ese momento y la incidencia de la configuración formal para facilitar el acceso a la información. Respondiendo a esta misma preocupación, comenzaron a surgir algunos otros estudios de enfoque comparado, con el énfasis puesto en las diferencias de alcance y calidad de las LAI. ${ }^{14}$

Ahora bien, juzgar la fortaleza legal de las normas de acceso a la información pública puede ser engañoso, como señala Michener: "Laws may be excellent on paper, and dysfunctional in practice". ${ }^{15}$ Sin embargo, aunque una ley robusta es insuficiente para asegurar el acceso a la información, es innegable que un respaldo normativo sólido es un elemento indispensable para garantizarlo, lo que justifica la necesidad de realizar estudios comparados en torno a estos instrumentos formales. Como señala Schedler, ${ }^{16}$ el establecimiento de una institución ocurre en dos etapas: primero emerge la formal, y luego se entabla la lucha por su efectividad; y aunque las dos etapas son cruciales, la naturaleza inercial de las instituciones provoca que una fase condicione la siguiente. ${ }^{17}$ Así, una ley de alta calidad en la dimensión formal es el mejor predictor de su efectividad futura. ${ }^{18}$ Otra razón importante para centrar este texto en la dimensión formal es que las leyes escritas se erigen en un elemento simbólico, a partir del cual el gobierno lanza señales deliberadas sobre su compromiso con ciertos temas. De esa forma, independientemente de su efectividad, las instituciones formales también tienen un valor como "adornos de aparador" independientemente de

${ }^{14}$ De Michener, "FOI Laws Around the World" y "The Surrender of Secrecy"; y de Toby Mendel, Amending Access to Information Legislation: Legal and Political Issues, París, Unesco, 2008; The Right to Information in Latin America: A Comparative Legal Survey, Quito, Unesco, 2009, disponible en http://portal.unesco.org/ci/ en/ev.phpURL_ID=28958\&URL_DO=DO_TOPIC\&URL_SECTION=201.html

${ }^{15}$ Michener, "The Surrender of Secrecy", p. 11.

${ }^{16}$ A. Schedler, “Authoritarianism's Last Line of Defense”, Journal of Democracy, vol. 21, núm. 1, 2010, p. 70.

${ }^{17}$ Pierson, op. cit.

18 Michener, "The Surrender of Secrecy”, p. 148. 
su capacidad de cumplimiento (window dressers ${ }^{19}$ ), lo que incentiva a los políticos a su elaboración: la simple promulgación de una ley de este tipo genera dividendos y lanza señales importantes, por la carga simbólica relevante que implica.

En este texto, una LAI de calidad se entiende como un instrumento normativo que obliga a todos los entes públicos a proveer información, que establece reglas y procedimientos claros y expeditos para solicitar información, que contempla instrumentos de apelación o inconformidad, un número mínimo de excepciones al acceso y disposiciones para la apertura proactiva. ${ }^{20}$

A la fecha, aún existen relativamente pocos indicadores internacionales que permitan acercarnos de manera directa a las diferencias en la calidad de las LAI. En este trabajo se eligió el Right to Information Rating (RTI), elaborado por el Centre for Democracy and Law y Access Info Europe, por varias razones. En primer lugar, cuenta con una cobertura mundial, que abarca prácticamente la totalidad de las LAI existentes (97\% para su edición de 2013). Además, está centrado en el instrumento normativo, y a diferencia de otros índices que abordan la transparencia o el combate a la corrupción de manera agregada, permite aislar este componente y analizarlo desde su dimensión formal. Finalmente, la actualización continua de su portal electrónico facilita el estudio de reformas o aprobaciones recientes.

El RTI se elabora desde 2010. En la edición de 2013 incluyó 97 leyes de acceso a la información. Tal y como Toby Mendel, director ejecutivo del Centre for Democray and Law, lo describe: el RTI "es un conjunto de estándares de mejores prácticas, que resulta en una rigurosa valoración de marcos legales, basado en los más altos referentes internacionales y comparativos. [...] El valor del RTI Rating es que señala fortalezas y debilidades precisas del marco legal, enfocando la atención hacia las áreas que lo requieren". ${ }^{21} \mathrm{La}$

${ }^{19}$ Helmke, Gretchen y Levitsky, Informal Institutions and Democracy: Lessons from Latin America, Baltimore, Johns Hopkins University Press, 2006.

${ }^{20}$ Michener, "The Surrender of Secrecy"; Mendel, RTI Rating Data Analysis Series...; Organización de Estados Americanos, Ley Modelo Interamericana sobre Acceso a la Información, 2010.

${ }^{21}$ Mendel, RTI Rating Data Analysis Series..., p. 1. 
vocación práctica de este índice le ha permitido ser utilizado en algunos procesos de reforma.

En términos de su metodología, el RTi evalúa siete aspectos formales de las LAI, a cada una de los cuales se le asigna un puntaje, que suman un máximo de 150 puntos, tal y como se muestra en la tabla 1. Los puntajes asignados a cada país se comparten con expertos locales en acceso a la información, para asegurarse de que todos los aspectos legales y normativos hayan sido considerados. ${ }^{22}$

\begin{tabular}{lc}
\multicolumn{2}{c}{ TABLA 1 } \\
Integración de puntajes del RTi Rating \\
\hline \multicolumn{1}{c}{ Categoría } & Puntaje Máximo \\
\hline Derecho de acceso & 6 \\
Sujetos incluidos & 30 \\
Procedimientos de acceso & 30 \\
Excepciones & 30 \\
Apelaciones & 30 \\
Sanciones & 8 \\
Medidas de promoción & 16 \\
& Total
\end{tabular}

Fuente: Mendel, RTi Rating Data Analysis Serie...

En su última edición, el RTI colocó a poco más de la mitad de las LAI evaluadas en el segundo tercil de puntaje (49 LAI obtuvieron entre 70 y 102 puntos), siendo la categoría con mejor desempeño la Cobertura, y la peor, las Sanciones y Protecciones, que en promedio sólo alcanza $33 \%$ del máximo posible. ${ }^{23}$

Los resultados completos para 2013 pueden consultarse en el anexo 1 de este documento. Para efectos de nuestro análisis, basta, por el momento, con revisar los países que ocupan las posiciones extremas de este índice, que se muestran en la tabla 2:

${ }^{22}$ Ibid., p. 4.

${ }^{23}$ Ibid., p. 5. 
TABla 2

Posiciones extremas del RTI

\begin{tabular}{rlc}
\hline No. & País & Puntaje \\
\hline 1 & Serbia & 135 \\
2 & Eslovenia & 129 \\
3 & La India & 128 \\
4 & Liberia & 124 \\
5 & El Salvador & 122 \\
6 & Sierra Leona & 122 \\
7 & México & 117 \\
8 & Antigua & 116 \\
9 & Maldivas & 116 \\
10 & Azerbaiyán & 115 \\
$\ldots$ & & \\
90 & Bélgica & 59 \\
91 & Taiwán & 58 \\
92 & Italia & 57 \\
93 & Jordania & 53 \\
94 & Alemania & 52 \\
95 & Tayikistán & 49 \\
96 & Liechtenstein & 39 \\
97 & Austria & 37 \\
\hline
\end{tabular}

Fuente: Elaboración propia con datos de RTI 2013.

A pesar de que a la fecha hay cien leyes formalmente aprobadas, únicamente se habían incluido 97 para el informe de RTI para 2013.

2. Explicando la calidad de las Leyes de Acceso a la INFORMACIÓN: VARIABLES ESTÁTICAS

¿Cómo explicar la variación en los niveles de calidad de las LAI? Como se ha mencionado líneas más arriba, pocos estudios se han dedicado a explorar los elementos que inciden en la calidad de estos instrumentos. 
En este apartado se exploran explicaciones basadas en lo que llamaremos "indicadores estáticos". Por indicadores estáticos se entienden aquéllos que proporcionan información sobre el nivel que presenta una variable en un momento determinado. Son una especie de "fotografías instantáneas" que nos permiten conocer cómo se desempeñó la unidad de análisis al hacer un corte preciso en el tiempo, y son los indicadores que se utilizan con más frecuencia para elaborar explicaciones causales. Ejemplo de ellas son: el nivel de ingresos de un país, el número efectivo de partidos en un parlamento, el grado de desigualdad, etc. Estas variables proveen información sobre la economía, la fragmentación política o la desigualdad, respectivamente, que existen en un momento dado, sin importar lo que haya sucedido antes o después de ese momento, tal y como una fotografía "congela" la acción en el instante de ser tomada.

En este texto se ensayan dos explicaciones basadas en este tipo de indicadores para determinar su influencia sobre la calidad de las LAi. La primera de ellas busca correlacionar la fortaleza de su LAI con el grado de democracia que existe en un país; y la segunda, con el nivel de libertades políticas presentes. Debido a que se busca dar una explicación plausible para las 97 LAI que fueron evaluadas por el RTI, se decidió utilizar modelos estadísticos de correlación bivariada y regresión lineal simple. Dado que se requerían indicadores de cobertura mundial para 2013, para ambas variables se tomaron los datos provistos por Polity $I V$ y por Freedom House.

\section{a. Explicaciones basadas en la calidad de la democracia}

Una de las primeras intuiciones que aparece cuando se habla de acceso a la información y transparencia es que éstas se encuentran en relación directa con el nivel de democracia que tiene un país. La opacidad y el secreto se conciben como el hábitat natural de los regímenes autoritarios, escenarios en los que la ausencia de la mirada pública permite que se pueda incurrir en el amplio abanico de manifestaciones del abuso del poder público. En oposición, la 
democracia, como el gobierno del pueblo, debe proveer de instrumentos para asegurarse que los funcionarios públicos cumplan con el mandato que les fue asignado en las urnas, de manera directa o indirecta; "puesto que en la democracia el poder emana de la mayoría, los gobernados necesitan evaluar el desempeño de los gobernantes, conocer sus acciones". ${ }^{24}$ Para Bobbio, es imposible que la democracia "pueda excluir de sus connotados la visibilidad o transparencia del poder". ${ }^{25}$ Igualmente, la reducción de espacios de arbitrariedad por efecto del establecimiento de controles y contrapesos es un rasgo característico de las democracias avanzadas. El poder de la información como control potencial es innegable desde esta interpretación.

Como se señaló en el apartado anterior, que el auge de las LAI y las transiciones a la democracia coincidan en el tiempo no es casual; si en un primer momento la importancia del acceso a la información se interpretaba en cuanto constituía un instrumento para alcanzar algo más (eficiencia administrativa, certeza financiera), en el discurso actual el acceso a la información se ha constituido en un elemento inherente a las democracias e indisociable a ellas, de tal modo que en contextos de transición es extraño pensar en un paquete de reformas políticas y administrativas derivado del desmantelamiento de un régimen autoritario que no incluya la aprobación o reforma de una LAI.

Por todo lo anterior, se podría pensar que mientras más consolidada se encuentre una democracia, más robustas serían las bases legales para acceder a la información pública. Las democracias avanzadas se caracterizan por altos grados de fortaleza institucional; de este modo, como las LAI constituyen una de las últimas creaciones institucionales ligadas a regímenes democráticos, la hipótesis establecería que países democráticos tendrán casi, por definición, instrumentos sólidos que permitan un acceso ágil y expedito para realizar solicitudes de información.

${ }^{24}$ J. A. Aguilar, Transparencia y democracia: claves para un concierto, México, IFAI, 2006.

${ }^{25}$ N. Bobbio, El futuro de la democracia, México, FCE, 1986. 


\section{b. Explicaciones basadas en las libertades}

El segundo conjunto de explicaciones detrás de la calidad de las LAI es el grado de libertades que existen dentro de un país. Esta argumentación supone considerar factores adicionales al funcionamiento de las instituciones políticas, que son en los que se centra la explicación anterior.

Esta explicación argumenta que el derecho de acceso a la información no puede concebirse como un elemento solitario; más bien, forma parte de un entramado de otros derechos, libertades y garantías. Jurídicamente, la concepción del acceso a la información como un derecho fundamental de los ciudadanos depende de la posibilidad de darle contenido, calidad y sustancia a otros derechos fundamentales. En ese sentido, el acceso la información cobra sentido cuando habilita un ejercicio más fluido de otros derechos, por ejemplo, cuando favorece un mejor ejercicio del sufragio, activo o pasivo, ${ }^{26}$ o cuando se lo concibe ligado a la libertad de expresión.

Bajo esta óptica, diríamos que ciudadanos que habitan en entornos más libres y con más garantías para ejercer sus derechos, son ciudadanos capaces de allegarse más y más diversa información. La hipótesis que se deriva de esta explicación es que en países más libres existirían instrumentos normativos más robustos que garantizaran un acceso a la información gubernamental más expedito.

Para poner a prueba los argumentos anteriores, se toma, por un lado, la dimensión de gobernanza propuesta por Polity $I V$ para 2013. Como se sabe, este índice toma valores entre -10 (autocracia plenamente institucionalizada) y +10 (democracia plenamente institucionalizada), a partir de la consideración de elementos como la calidad de las instituciones y procedimientos políticos, las restricciones sobre el Ejecutivo y la competencia política. Por otro lado, se tomaron los indicadores de derechos políticos y libertades ciudadanas que se incluyen en el índice de Freedom House para 2013, el

${ }^{26}$ Miguel Carbonell, "El derecho de acceso a la información como derecho fundamental”, en S. López-Ayllón (coord.), Democracia, transparencia y Constitución, México, UnAm-IfaI, 2006, p. 7. 
cual utiliza una escala del 1 (pleno ejercicio de derechos o libertades) al 6 (nulo ejercicio de derechos o libertades). Así, al considerar los valores provistos por estos índices, logramos tomar una "fotografía global" del estado de la democracia y de las libertades y derechos políticos presentes en los 97 países que para 2013 contaban con una LAI.

Se ensayaron dos modelos estadísticos para probar las argumentaciones desarrolladas: el primero es una correlación bivariada entre el nivel de democracia que arroja Polity $I V$ y los resultados de la calidad de la LAI. El segundo es una regresión lineal simple con los valores para libertades civiles y derechos políticos de Freedom House como variables independientes, buscando su relación con la calidad de la LAI. Los resultados obtenidos se expresan en la tabla 3.

TABla 3

Modelos de Correlación Bivariada/Regresión Lineal Simple para los correlativos del puntaje total obtenido en el

Right to Information Rating

\begin{tabular}{lcc}
\hline Variables independientes & Modelo 1 & Modelo 2 \\
\hline Nivel de democracia & -.053 & \\
(Polity IV) & $(.634)$ & \\
& & -.911 \\
Derechos políticos & & $(.806)$ \\
& & 3.683 \\
Libertades civiles & & $(.351)$ \\
Coef. Pearson $/ \mathrm{R}^{2}$ & -.053 & .042 \\
\hline $\mathrm{N}$ & 95 & 95
\end{tabular}

Para las correlaciones se expresan coeficientes de Pearson; para las regresiones lineales, coeficientes no estandarizados. Entre paréntesis se expresan los valores $p$.

La variable dependiente es el puntaje obtenido por cada LAI de un máximo posible de 170 .

$* * * \rho \leq 0.01 ; * * \rho \leq 0.05 ; * \rho \leq 0.10$

Como se puede inferir a partir de estos resultados, no existe una relación estadísticamente significativa entre el nivel de democracia 
de un país y la calidad de su instrumento normativo para acceder a la información. De igual modo, tampoco el grado de libertades y derechos civiles parece estar relacionada, con la configuración formal de las LAI. Así, aunque no son los únicos elementos que podrían probarse, estos resultados demandan una explicación distinta para la calidad de las LAI.

Estadísticamente, parece que las aproximaciones que se basan en indicadores estáticos no alcanzan a explicar de manera cabal las dinámicas detrás de la confección o de la evolución de un instrumento normativo que, sobra decir, se ha conceptualizado, adoptado y adaptado de manera muy distinta en cada país que se ha implementado, y en cada momento de implementación, a pesar de los evidentes procesos de difusión y contagio, y del impulso promovido por organismos internacionales.

Explicaciones dinámicas: el tiempo de la transparencia como acumulación de aprendizaje y trayectorias políticas

En este apartado se exploran explicaciones basadas en elementos dinámicos. De forma opuesta a lo que constituyen los indicadores estáticos, según se entienden aquí, las explicaciones dinámicas no toman como referencia lo que sucede en un momento fijo en el tiempo, sino que toman como eje las trayectorias y los legados políticos, institucionales, históricos, etc. Así, más que ocuparse de las magnitudes que presentan determinados indicadores para un momento, estas explicaciones se preocupan por el origen de dichas magnitudes y su significado en cuanto efectos temporales. De manera figurada, podemos decir que si las explicaciones estáticas toman fotografías de un instante determinado, las explicaciones dinámicas hacen una videograbación, en la que lo relevante es precisamente el movimiento, como un factor que sólo cobra significado si se inserta dentro de una dimensión temporal.

Estas explicaciones dinámicas resultan especialmente atractivas para analizar las LAI, porque hablar de "la explosión de la transparencia" necesariamente remite a nociones de contagio y difusión, que llevan implícita una dinámica temporal: ¿cuánto tiempo tomó este proceso?, ¿qué implicaciones tiene haberse sumado a la ola de difusión antes o haberlo hecho al final? El tiempo es el telón de fondo sobre el que se escribe la historia de los 
procesos que se transfieren de lugar a lugar. Sin embargo, en el estudio de la transferencia de políticas, el tiempo ha sido una "dimensión negada”, ${ }^{27}$ excluida o subordinada en el análisis, a pesar de que, para pensadores clásicos como Marx, Tocqueville o Weber los patrones histórico-temporales formaban una parte esencial de las explicaciones políticas y sociales. Como ha señalado Pierson, ${ }^{28}$ ubicar a las políticas en su dimensión temporal puede enriquecer significativamente las explicaciones sobre sus causas y consecuencias.

Schedler y Santiso proponen dos perspectivas para integrar el tiempo como "variable normal" al análisis de política. ${ }^{29}$ Por un lado, abogan por concebir al tiempo como horizonte de referencia; es decir, como un elemento para ubicar cronológicamente el desarrollo de los acontecimientos, sus ritmos y su duración. Desde esta perspectiva se asume, por ejemplo, que los "ritmos" 30 o las secuencias $^{31}$ con que se ponen en marcha determinadas políticas condicionan sus resultados.

La segunda perspectiva propuesta por estos autores concibe al tiempo como un recurso escaso, no renovable y susceptible de ser administrado por los actores sociales. Aprovechar momentos clave para actuar con oportunidad, o bien, desgastar a la oposición acelerando o ralentizando procesos de toma de decisiones constituyen estrategias recurrentes que pueden incorporarse como elementos de análisis, bajo esta propuesta temporal.

En el mismo sentido, para el campo de la gestión pública, Pollitt ha señalado que, a causa de las teorías genéricas de gerencialismo

${ }^{27}$ M. Dussauge, "The Neglected Dimension: Bringing Time Back into CrossNational Policy Transfer Studies”, Policy Studies, vol. 33, núm. 6, 2012, pp. 567-585; E. Page, "Future Governance and the Literature on Policy Transfer and Lesson Drawing”, ESRC Future Governance Papers, 2000.

${ }^{28}$ Op. cit.

${ }^{29}$ Schedler y Santiso, art. cit.

${ }^{30}$ A. Jacobs, "The Politics of When: Redistribution, Investment and Policy Making for the Long Term”, British Journal of Political Science, vol. 38, núm. 2, 2008, pp. 193-220.

31 T. Falleti, “A Sequential Theory of Descentralization: Latin American Cases in Comparative Perspective", American Political Science Review, vol. 99, núm. 3, 2005, pp. 327-346. 
que buscan ser válidas en todos los entornos, el tiempo no sólo ha sido relegado, sino que se ha visto como noción conflictiva. ${ }^{32}$ Nociones como "rutinas administrativas" y "resistencias al cambio" sugieren que todo lo distinto al momento presente es visto como un lastre. El pasado tiene mala reputación.

Sin embargo, Pollitt también aboga por reinsertar la variable temporal al estudio de la gestión pública para ganar en precisión y realismo. El pasado, y por ende las nociones temporales, son elementos que no pueden sencillamente omitirse del análisis en tanto marcan restricciones sobre el presente y, en gran medida, lo explican.

No es la intención de este texto realizar un repaso exhaustivo de la bibliografía que ha resaltado la importancia de incluir al tiempo en el análisis de la política y las políticas; baste con decir que es creciente el número de autores que coinciden en señalar que las variables temporales proveen elementos de precisión para abordar de manera más fiel elementos complejos, tales como la variedad de regímenes políticos, ${ }^{33}$ las decisiones de implementación, ${ }^{34}$ la integración regional, ${ }^{35}$ la transferencia de políticas ${ }^{36}$ o la evaluación de políticas. ${ }^{37}$

Meyer-Sahling realiza un "inventario" de las formas en las que el tiempo afecta la gobernanza, tomando como referencia las políticas de la Unión Europea. ${ }^{38}$ Encuentra por lo menos seis áreas de distinción del tiempo, entre las que se incluyen dieciséis dimensiones de temporalidad, cuatro niveles de temporalidad y dos formas de utilizar el tiempo para el análisis. Ello da una idea de la amplitud

32 Pollitt, op. cit.

33 J. Linz, "Democracy's Time Constraints", International Political Science Review, vol. 19, núm. 1, 1998, pp. 19-37.

${ }^{34}$ Jacobs, art. cit.

${ }^{35}$ K. Goetz, "How Does the EU Tick? Five Propositions on Political Time", Journal of European Public Policy, vol. 16, núm. 2, 2009, pp. 202-220.

${ }^{36}$ Dussauge, "The Neglected Dimension...".

${ }^{37}$ N. Bressers, E. Ten Heuvelhof y M. Van Twist, "Exploring the Temporal Dimension in Policy Evaluation Studies”, Policy Sciences, vol. 31, núm. 3, 2013, pp. 319-330.

${ }^{38}$ J.-H. Meyer-Sahling, “Time and European Governance: An Inventory”, trabajo presentado en la Biennal Conference of the European Studies Association, Montreal, 2007. 
del abanico de elementos que se están dejando fuera cuando se estudia una política de manera "estática" y se niega la influencia de estos elementos dinámicos.

Sumándome a quienes han resaltado la importancia de las variables temporales para enriquecer el análisis de la política, en este estudio se propone que la calidad de las LAI está condicionada por el tiempo desde dos perspectivas. La primera recupera una de las propuestas de Schedler y Santiso al considerar al tiempo como un horizonte temporal: ${ }^{39}$ se argumenta que los países que se incorporan a la oleada del acceso a la información en momentos posteriores cuentan con más recursos para confeccionar una ley sólida, en lo formal. Esto tiene que ver con distintos procesos de aprendizaje y evolución del concepto de acceso a la información, que se desarrollan más abajo.

La segunda perspectiva considera los legados del tiempo en el ideario y las expectativas colectivas como elementos que afectan la fortaleza de la LAI: los países que se encuentran en tránsito a la democracia y que están lidiando con una larga tradición de secretismo en la esfera político-administrativa tendrán más incentivos para aprobar una LAI robusta formalmente, para ondearla como una bandera de renovación política y moral, y esgrimirla como símbolo del compromiso con los valores democráticos.

\section{a. Tiempo como horizonte de referencia y acumulación de conocimiento}

La primera perspectiva se relaciona con la propuesta de Schedler y Santiso de integrar al tiempo en el análisis como "horizonte de referencia". ${ }^{40}$ Bajo este enfoque, se propone que el paso del tiempo provee una acumulación de experiencias y aprendizaje, no sólo de los detalles teóricos y normativos de lo que constituye a una LAI sólida, sino de los criterios con que se han evaluado estos instrumentos, los dividendos y las consecuencias políticas que han traído consigo en otros entornos. Esto hace de la difusión todo menos un

${ }^{39}$ Art. cit.

${ }^{40}$ Loc. cit. 
fenómeno homogéneo: las variables no se transfieren de manera constante a lo largo del tiempo, de modo que los elementos que habrán privilegiado las primeras LAI serán distintos a los que se enfaticen en las más recientes. ${ }^{41}$

La expansión de las LAI siguió la trayectoria en "S" típica de la difusión de políticas. ${ }^{42}$ Ese esquema propone que, después de un determinado punto en el tiempo, la evidencia sobre la relevancia o la pertinencia de cierta innovación se vuelve suficientemente vigorosa como para desatar un incremento dramático en la tasa de adopción de dicha innovación. ${ }^{43}$

Esto parece ajustarse bien a lo que sucedió con las LAI: las primeras leyes (Suecia, Finlandia y Estados Unidos) quedan muy remotas respecto de la ola de aprobaciones que se registraría en la década de 1990. Previo a 1999, la tasa de adopción de las LAI era baja y relativamente estable (menos de veinte leyes en todo el mundo hasta 1996), y además la totalidad de las leyes existentes pertenecía a democracias desarrolladas. En los siguientes diez años se registró la "explosión de la transparencia" y la tasa de aprobación de LAI creció a ritmos inéditos. Entre 1999 y 2009 se aprobaron prácticamente todas las LAI existentes en el mundo (más de 80), que se distribuyen a partes prácticamente iguales entre los países de Europa del Este y Europa Central, y los países de América Latina y Asia. Ese lapso de diez años -el periodo comprendido entre 1999 y 2009- corresponde a la "cresta de la ola de transparencia" con un incremento dramático en la proporción de LAI aprobadas, después del cual la tasa de aprobación volvió a un ritmo más o menos estable hasta el día de hoy. Esto puede apreciarse en la gráfica 1:

A pesar de la difusión en "S" de las LAI, hay varios factores que hacen pensar que el modelo clásico de difusión no se ajusta bien al caso de las LAI. Roberts señala que este enfoque no está bien equipa-

${ }^{41}$ J. Jordana, X. Fernández y D. Levi-Faur, "The Global Diffusion of Regulatory Agencies: Channels of Transfer and Stages of Diffusion”, Comparative Political Studies, vol. 44, núm. 10, 2011, pp. 1343-1369.

42 E. Rogers, Diffusion of Innovations, Nueva York, Free Press, 1995; K. Weyland, Bounded Rationality and Policy Diffusion: Social Sector Reform in Latin América, Princeton, Princeton University Press, 2007.

${ }^{43}$ Roberts, art. cit., p. 4. 
do para hacer frente a la alta heterogeneidad de los adoptadores potenciales de las LAI, y especialmente a las condiciones cambiantes de algunos de ellos. ${ }^{44}$ La naturaleza de los países que conforman el repunte de la ola-regímenes emergiendo de la caída de la Unión Soviética o de regímenes autoritarios que buscaban "consolidar un compromiso con la democratización lo más pronto posible" 45 - hacían que sus características institucionales, socioeconómicas y políticas fueran inestables, de tal modo que no podía hablarse de transferencia convencional.

\section{GRÁFICA 1}

Crecimiento en el número de LAI a lo largo del tiempo

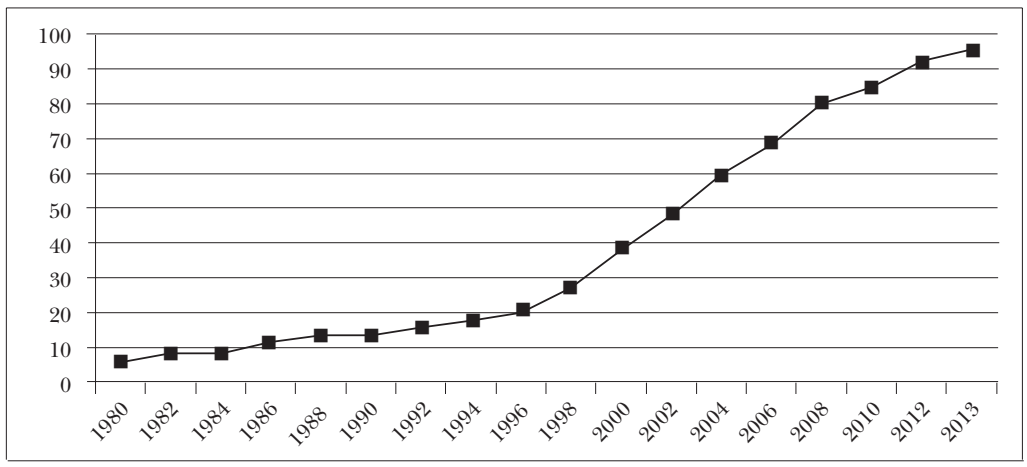

Fuente: Mendel, RTI Rating Data Analysis Series...

Otra dificultad es que el enfoque tradicional de difusión no alcanza a explicar las variaciones en las leyes adoptadas: el contagio regional sólo puede dar cuenta de la expansión de las LAI, pero no del nivel de calidad que éstas presenta, preocupación central de este texto. Como señala Dussauge, ${ }^{46}$ la gran mayoría de los trabajos de difusión y transferencia están enfocados en el "qué se transfiere" o "quiénes están involucrados", pero esa discusión ha dejado de

\footnotetext{
${ }^{44}$ Roberts, art. cit., p. 5.

${ }^{45}$ Ibid., p. 6.

${ }^{46}$ Dussauge, "The Neglected Dimension...”, p. 568.
} 
lado los asuntos del "cuándo se transfiere", crucial para armar explicaciones más logradas de la variación en una misma política.

La difusión de las Lai no sólo tiene que ver con que en determinado momento ${ }^{47}$ la transparencia y el acceso a la información pasaron a ser elementos clave para culminar las transiciones a la democracia y los procesos de liberalización e integración económica, ${ }^{48}$ sino también con un proceso de observación por parte de los países interesados en poner en marcha una LAI, lo que remite a nociones cognitivas de aprendizaje de políticas. Sin embargo, hay que dejar claro que el paso del tiempo no equivale necesariamente a acumular lecciones de configuración técnica de cómo hacer una mejor ley; también hay un aprendizaje en términos de cuáles son los criterios que privilegian las evaluaciones de referencia, y cuáles han sido las consecuencias -positivas y negativas- de haber implementado cierto tipo de LAI, con determinadas disposiciones y candados. En pocas palabras, los países aprenden también "a copiar mejor": seleccionan con más cuidado el modelo a seguir y adoptan los elementos que otorgan notoriedad, en términos de evaluación internacional.

Paralelamente a este proceso de aprendizaje, a lo largo del tiempo también se registra una evolución de los conceptos en torno a los cuales se construyen las LAI. Las primeras regulaciones sobre acceso a la información no se insertaban todavía en la discusión de la interacción entre transparencia y democracia, y menos aún concebían el acceso a la información como una prerrogativa ciudadana con contribuciones puntuales a los mecanismos de vigilancia y combate a la corrupción. Michener distingue tres olas de difusión de las LAI en América Latina, cada una de las cuales responde a diferentes conceptualizaciones y fines aludidos al acceso a la información. ${ }^{49}$ Estas nociones bien pueden trasladarse a la expansión de las LAI en todo el mundo. En la primera oleada, que

${ }^{47}$ A finales de los noventa, si seguimos a Colin Bennett, "Understanding Ripple Effects: The Cross-National Adoption of Policy Instruments for Bureaucratic Accountability", Governance, vol. 10, núm. 3, 1997, pp. 213-233; Michener, "The Surrender of Secrecy"; Roberts, art. cit.

${ }^{48}$ Roberts, art. cit., passim.

${ }^{49}$ Michener, "The Surrender of Secrecy", p. 24 y ss. 
Michener ubica entre 1969 y 1995, ${ }^{50}$ el acceso a la información era materia de expertos en temas muy específicos: se hablaba, por ejemplo, de la posibilidad de acceder a información ambiental (Declaración de Río de 1992) o de poner a disposición de la prensa canales para facilitar de manera más ágil a información útil para desempeñar su labor (Declaración de Chapultepec, 1994). No existía una noción del acceso a la información como un derecho extendido; más bien se lo concebía como una herramienta para contribuir a resolver las demandas de grupos particulares.

La segunda oleada coloca a la transparencia y el acceso a la información como elementos que complementaban la liberalización económica. ${ }^{51}$ Proveer garantías para el acceso a la información suponía abonar mayor certidumbre y estabilidad a los mercados. Las instituciones financieras internacionales se constituían en las principales impulsoras de la adopción de LAI como una recomendación para resolver las crisis en las que diversos países de América Latina se vieron sumidos durante la década de 1990.

Finalmente, la tercera oleada está caracterizada por un discurso del acceso a la información como derecho ciudadano y como componente irreductible de la democracia. Es en ese periodo en el que la transparencia y el acceso a la información se conciben como prerrogativa de la ciudadanía extendida y se demandan por su valor como fines en sí mismos, y no necesariamente como medios para alcanzar algo más. Durante este periodo, resalta el papel de organismos internacionales de naturaleza no financiera para impulsar la aprobación de las LAI y esta concepción del acceso a la información. La Ley Modelo de Transparencia elaborada por la Organización de Estados Americanos (OEA), o los precedentes que ha ido estableciendo la Comisión Interamericana de Derechos Humanos en diversas resoluciones, ${ }^{52}$ dan muestra de lo anterior.

50 Loc. cit.

${ }^{51}$ Roberts, art. cit.

${ }^{52}$ Entre las que destaca el fallo de la Corte Interamericana de Derechos Humanos en Claude Reyes vs. Chile, que reconoció formalmente el derecho de acceso a la información como parte del derecho fundamental a la libertad de expresión. 
La mayor parte de los índices que evalúan a las LAI se han elaborado durante los últimos años, de manera que sus criterios coinciden con la noción detrás de la última oleada: el acceso a la información como derecho de la ciudadanía extendida. De ahí que no sea casual que las leyes elaboradas en las últimas fechas se ajusten mejor a los criterios de evaluación de calidad, como los que incluye el RTI.

De manera análoga a lo que se realizó para las hipótesis derivadas de factores estáticos, para comprobar formalmente la posibilidad de que exista una relación entre la fecha de aprobación de una LAI y su calidad, se probó una correlación bivariada entre estas variables, cuyos resultados se expresan en la tabla 4 .

\section{TABLA 4}

Correlación Bivariada entre puntaje total obtenido en el Right to Information Rating y fecha de aprobación de la LAI

\begin{tabular}{lc}
\hline \multicolumn{1}{c}{ Variables independientes } & Modelo 3 \\
\hline Fecha de aprobación & $.251^{* * *}$ \\
de la LAI & $(.014)$ \\
\hline $\mathrm{N}$ & 95
\end{tabular}

$\mathrm{N}=95$ porque se dejan fuera las LAI de Suecia (1766) y Finlandia (1951) para evitar sesgos muestrales.

Se expresan coeficientes de Pearson. Entre paréntesis se expresan los valores p.

La variable dependiente es el puntaje obtenido por cada LAI de un máximo posible de 170 .

$* * * \rho \leq 0.01 ; * * \rho \leq 0.05 ; * \rho \leq 0.10$

Del análisis anterior, puede afirmarse que, efectivamente, existe una relación positiva y estadísticamente significativa entre la fecha de aprobación de las LAI y su calidad. De hecho, pareciera que cada año transcurrido aporta poco más de un cuarto de punto en la calidad de la LAI, según los criterios de evaluación utilizados en el RTI.

Por los efectos de aprendizaje técnico, copia selectiva y evolución conceptual, las leyes más recientes se adaptan mejor a los criterios de calidad considerados por índices como el RTI. 


\section{b. Los trazos del tiempo como reacción ante los legados del pasado}

La segunda argumentación basada en dinámicas temporales está relacionada con los usos simbólicos de la transparencia para "marcar el inicio de una nueva era", al lanzar señales de compromiso con la democracia, y la lucha contra la corrupción y la opacidad administrativa. Es decir, se propone que los legados históricos condicionan el tipo de LAI aprobada, al verse ésta como una herramienta útil para cerrar capítulos de oscuridad y secreto e iniciar el futuro con una nueva dinámica política.

Uno de los aspectos más llamativos del RTI es que los primeros diez lugares están ocupados por democracias jóvenes o en consolidación, mientras que muchas de las democracias más antiguas y estables se encuentran en los últimos sitios del conteo.

Líneas más arriba se hablaba de la aparente paradoja entre el nivel de democracia y la calidad del marco normativo de acceso a la información, que deja de serlo, al menos en parte, cuando introducimos variables forjadas en torno al tiempo. Hablar del nivel de democracia que presenta un país en un momento determinado equivale a congelar una imagen, que no puede decirnos mucho sobre lo que sucedió previo a ese instante, ni de las condiciones que lo construyeron. El valor del tiempo como variable explicativa reside, también, en rastrear historias y re-armar trayectos institucionales. Goetz y Meyer-Sahling ${ }^{53}$ señalan la relevancia del tiempo como elemento simbólico desde las perspectivas constructivistas: las visiones de los actores sobre las elecciones no están guiadas necesariamente por una racionalidad instrumental, sino por ideas y principios alimentados por valores y normas sociales, que sólo se engendran a largo plazo. Lo que se argumenta aquí es que el tiempo deja trazos en las instituciones, en las prácticas y en las rutinas, ${ }^{54}$ pero también en las concepciones y los significados comunes.

${ }^{53}$ K. Goetz y J.-H. Meyer-Sahling, "Political Time in the EU: Dimensions, Perspectives, Theories”, Journal of European Public Policy, vol. 16, núm. 2, 2009, p. 194

${ }^{54}$ Pierson, op. cit. 
Si tomamos las trayectorias -y no sólo los niveles- de estabilidad política e institucional, y de garantías a los derechos y libertades, es posible elaborar argumentos más elaborados que, sin dejar de lado factores relevantes como el grado de consolidación democrática de un país, aborden desde una perspectiva más amplia su incidencia sobre la calidad de las LAI.

Los países que encabezan el RTi son, en su mayoría, democracias en tránsito desde regímenes autoritarios o totalitarios, que experimentaron durante un periodo prolongado la negación de garantías individuales, y la administración de instituciones regidas bajo rutinas opacas y oscuras. En la gráfica 2 se muestra el repunte de aprobaciones de LAI que se experimentó en Europa del Este y América Latina a partir de la segunda mitad de la década de 1990. La coincidencia de esto con los procesos de desmantelamiento de regímenes autoritarios no es casual, que también se verifica, a partir de 2010 para los países árabes.

\section{GRÁFICA 2}

Número de LAI aprobadas por periodo y región

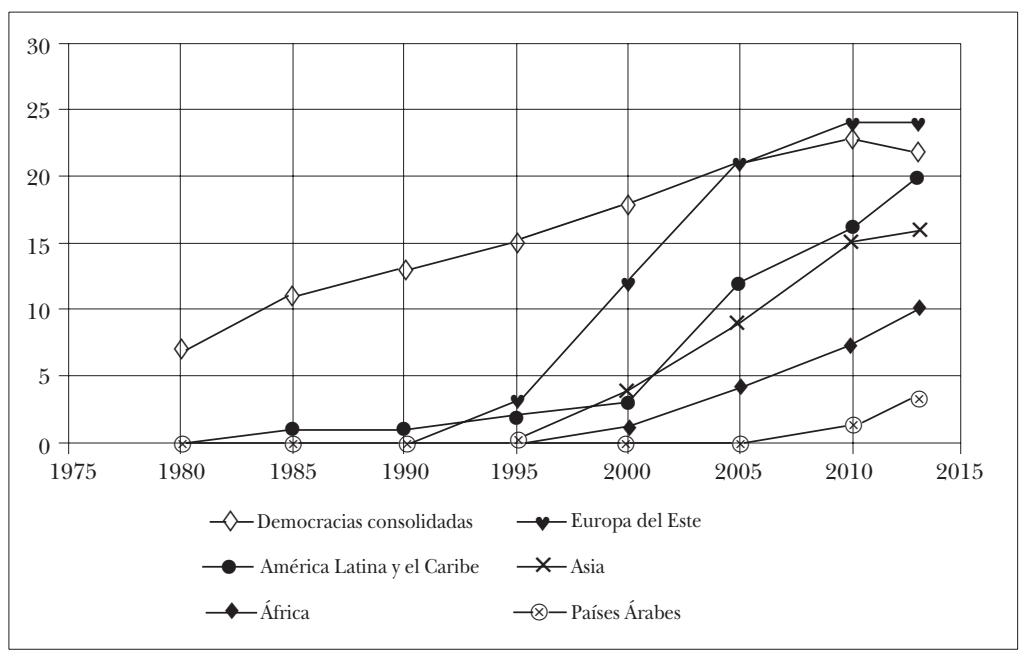

Fuente: Mendel, RTI Rating Data Analysis Series... 
Terminar con un régimen autoritario y emprender una transición a la democracia es una labor compleja, que requiere de cambios institucionales profundos y también de lanzar las señales adecuadas. Las variables temporales ayudan a entender cómo es que la transparencia y el acceso a la información son elementos esgrimidos de manera vigorosa por estas nuevas democracias y qué hay detrás del incremento en la tasa de aprobación en estas dos regiones específicas.

Retomando las oleadas de transparencia propuestas por Michener, podemos decir que bajo la tercera oleada, la construcción de instrumentos institucionales que garantizaran el acceso a la información se concibe como una condición indispensable para lograr un régimen democrático y como un derecho ciudadano exigible. La transparencia se erige como una de las prerrogativas irrenunciables que demandar a las "nuevas democracias", más allá del modelo puramente representativo; y también marca a las LAI como la alternativa para construir sistemas de acceso a la información. La transparencia se esgrime simbólicamente como la herramienta para combatir los vicios de corrupción y las trazas de un pasado autoritario. Y es que el tiempo vivido bajo regímenes autoritarios conduce a nociones de desconfianza tan amplias que es necesario demostrar, al menos simbólicamente, compromiso y voluntad con el tránsito a la democracia.

Aunque sería necesario realizar estudios de caso específicos para comprobar de manera formal la validez de este argumento, es frecuente encontrar aprobaciones de LAI que coinciden con la instauración de un gobierno de alternancia, o de transición. Esto ocurrió en Serbia o Eslovenia, donde se impulsaron LAI muy robustas después de haber salido de duros regímenes autoritarios y periodos de violencia. La LAI serbia, por ejemplo, se promulgó junto con la nueva Constitución de 2003, que marcó el final de las cruentas guerras de Croacia, Bosnia y Kosovo, y su separación de Montenegro. Así, el acceso a la información se integró a todo el nuevo marco normativo e institucional que inauguraba una nueva época. En ese sentido, Serbia no podía permitirse aprobar una ley endeble.

Otro buen ejemplo lo provee el caso mexicano: la alternancia de 2000, después de siete décadas de dominio priista marcaba la 
necesidad de una "renovación moral" y del establecimiento de "un nuevo código de ética, $[y]$ sustituir las reglas no escritas del viejo régimen cuya vigencia había sido rechazada implícitamente por los mexicanos el 2 de julio de 2000". ${ }^{55} \mathrm{El}$ acompañamiento de la sociedad civil y el reconocimiento de la oposición sobre la relevancia del instrumento también volvían inviable la aprobación de una LAI que no cumpliera un nivel aceptable de calidad; por ejemplo, mejorando el esquema de sanciones propuestas o incluyendo un sistema de apelaciones. ${ }^{56}$ Aprobar una LAI sólida, en consecuencia, se concebía como una de las mejores soluciones disponibles para marcar una ruptura con un pasado oscuro y autoritario, e inaugurar una nueva época de democracia y probidad.

Empero, el funcionamiento real de estos instrumentos es un asunto independiente: si bien la constitución formal de la norma nos da pistas de su efectividad, esta relación no es unívoca. De hecho, si se buscara analizar el funcionamiento de las LAI en entornos que provienen de instituciones opacas, con una administración que privilegia el secretismo, aparecería inmediatamente el peso del pasado: el path dependence complica terminar de un momento a otro con tradiciones administrativas arraigadas. Sin embargo, en términos estrictamente formales, es importante resaltar que una norma robusta en materia de transparencia y acceso a la información aporta mucho en términos simbólicos, y puede presumirse como credencial democrática.

En contraste, las naciones con una larga trayectoria democrática no se enfrentaban a un apremio semejante para aprobar una LAI robusta. Ello puede deberse a que en democracias estables exista una "equivalencia institucional" a lo que proveen las LAI de alta calidad. Tradiciones consolidadas de justificar las decisiones públicas, de contar con un control parlamentario vigoroso, con una Corte Suprema independiente o con medios libres y plurales, bien pueden reducir la necesidad de contar con una LAI robusta,

55 V. Flores, "Políticas públicas en México y la transición moral y pública", en Raúl Béjar Navarro (coord.), Las políticas públicas en la alternancia mexicana, México, unam, 2004, p. 24. También: A. Durazo, Saldos del cambio, México, Plaza Janés, 2006.

${ }^{56}$ López Ayllón, art. cit., pp. 19-20. 
pues es a través de los instrumentos anteriores que los habitantes de estos países pueden tener acceso a la información que necesitan para mejorar su toma de decisiones como ciudadanos. Más aún, no necesitan demostrar a nadie su compromiso con la democracia o con el ejercicio de derechos, de tal modo que quizás una LAI "blanda" sea más que suficiente para lubricar engranajes que, de hecho, ya están funcionando por sí mismos.

A pesar de esto, el realce que han ganado la transparencia y el acceso a la información en años recientes ha contagiado también a las democracias establecidas: a pesar de que las LAI configuradas bajo los criterios actuales quizás resulten accesorias para democracias consolidadas, también se han convertido en un elemento de rigueur para que un gobierno pueda presentarse como "progresista”. Las LAI constituyen entonces un elemento de auto-afirmación para las democracias consolidadas, más que una verdadera necesidad. ${ }^{57}$ Prueba de ello es que en las democracias que aparecen al final del listado se esté discutiendo la pertinencia de modificar sus LAI vigentes, para ajustarlas a los modelos más recientes. ${ }^{58}$

\section{Conclusiones}

Es innegable la relevancia que, en un corto periodo, han adquirido las LAI. Bien como parte integrante de entramados más complejos de combate a la corrupción, o bien, como reivindicación ciudadana, el acceso a la información es un tema que parece haber llegado para quedarse.

A pesar de la proliferación de normas que lo regulan en prácticamente todos los países del mundo, sabemos poco sobre las condiciones que afectan su contenido y menos aún sobre la evolución de este instrumento de política. Como el auge de las LAI ocurrió en un lapso breve, se ha subestimado la relevancia de las variaciones que

${ }^{57}$ Michener, “The Surrender of Secrecy”, pp. 19 y 21.

${ }^{58}$ Por ejemplo, en Austria, cuya LAI resultó la peor evaluada por el RTI, se está discutiendo desde 2013 un borrador para reformar la LAI vigente, con el acompañamiento de grupos ciudadanos. (http://www.freedominfo.org/regions/europe/austria/). En Canadá, que ocupa el lugar 56, está ocurriendo algo similar. 
presentan en el tiempo y el espacio. Se asume que hay leyes buenas y leyes no tan buenas, con lo que implícitamente se prescribe un solo modelo para acceder a la información gubernamental.

En este texto se ha abogado por una comprensión más amplia de los elementos que llevan a una LAI a ser de determinada manera y no de otra, mediante la introducción de variables temporales. El momento de aprobación de una LAI está cargado de una acumulación de aprendizaje técnico y político, de historias con las que se busca terminar, o bien, a las que se busca reforzar, y de cambios en la manera de concebir un mismo instrumento. Es ingenuo medir leyes viejas con varas nuevas: ello supone ignorar las huellas que imprime el paso del tiempo en las historias particulares de los países, y en los requisitos y los fines que adquiere una política. Como señala Michener: "Old laws, elaborated when only hazy standards existed, tend to lack the detail that might be expected of today's strong laws". 59

La introducción del tiempo en el análisis de las LAI permite repensar el descarte rápido de variables estáticas teóricamente relacionadas con la transparencia y el acceso a la información, como la calidad de la democracia o el grado de libertades presentes en un momento y un lugar determinado. A pesar de que la relación de estas variables con la calidad de las LAi parece plausible, el análisis estadístico desarrollado mostró que tomar "el aquí y el ahora como el único referente" 60 omite gran parte de la complejidad de los procesos de confección de LAI y nos impide entender a cabalidad qué circunstancias llevaron al tener determinada ley y no otra. En cambio, tomar en consideración las trayectorias de acumulación de aprendizaje o los legados que inevitablemente hereda el pasado arroja más luz sobre las motivaciones de los actores para construir una LAI robusta, o para no hacerlo.

Esta investigación, sin embargo, evidenció varios retos para las explicaciones forjadas en torno al tiempo. Uno de ellos es cómo dar cuenta de variaciones de la calidad de la misma ley: ¿qué factores están detrás de las reformas?, ¿qué papel desempeñan actores clave

${ }^{59}$ Michener, “The Surrender of Secrecy”, p. 11.

${ }^{60}$ Schedler y Santiso, art. cit., p. 7. 
como organizaciones de la sociedad civil, cuerpos burocráticos y legisladores? Una línea clara de investigación que se abre a ese respecto es la consideración del tiempo como un recurso estratégico para actores que calculan, buscando maximizar sus intereses. ${ }^{61}$

Otra línea de investigación abierta tiene que ver con los elementos puntuales de variación. Si bien en este texto el enfoque está puesto en la agregación de diferencias que se refleja en el puntaje total otorgado por el RTI, lo cierto es que cada criterio de evaluación tiene un significado y un peso distinto. Emprender este tipo de análisis supone avanzar un paso más desde lo formal a lo real: ¿qué implicaciones prácticas tiene regular a profundidad el alcance de las leyes, pero hacerlo de forma superficial en lo referente a las sanciones?, ¿qué intención tiene restringir la interposición de recursos?, ¿cómo debilita el acceso a la información contar con un esquema laxo de medidas de promoción?

Finalmente, las hipótesis esbozadas en este texto reclaman la elaboración de investigación más cualitativa sobre las condiciones particulares de cada país en el momento en que se impulsa o se reforma una LAI. Las tareas de reconstrucción de trayectorias, de detectar inercias y de comprender las sincronías de los actores no pueden realizarse de manera cabal más que adoptando un enfoque más microscópico. En última instancia, una de las mayores implicaciones de la introducción del tiempo al análisis es la comprensión de que hay un diálogo constante entre la historia de los países, la historia de las políticas y la configuración particular de estas últimas. El tiempo ha permanecido como testigo silencioso en la gran mayoría de los estudios de política, sin embargo, darle voz, manteniendo objetividad y eludiendo las explicaciones "a modo" no deja de ser una tarea desafiante.

\section{BiBLIOGRAFÍA}

Ackerman, J. e I. Sandoval, "The Global Explosion of Freedom of Information Laws", Administrative Law Review, vol. 58, núm. 1, 2006, pp. 85-130.

${ }^{61}$ Ibid. 
Aguilar, J. A., Transparencia y democracia: claves para un concierto, México, IFAI, 2006.

Banisar, D., "Freedom of Information and Access to Government Record Laws around the World", 2004, disponible en https://www.ndi.org/ files/2044_ww_freeinfo_010504.pdf, con acceso el 1 de diciembre de 2014.

—, "Freedom of Information around the World 2006: A Global Survey of Access to Government Record Laws", 2006, disponible en http:/ / www.freedominfo.org/documents/global_survey2006.pdf, con acceso el 1 de diciembre de 2014.

—, "National Comprehensive Data Protection/Privacy Laws and Bills 2014 Map”, SSRN, 2014.

Bennett, Colin, "Understanding Ripple Effects: The Cross-National Adoption of Policy Instruments for Bureaucratic Accountability", Governance, vol. 10, núm. 3, 1997, pp. 213-233.

Bobbio, N., El futuro de la democracia, México, FCE, 1986.

Bressers, N., E. Ten Heuvelhof y M. Van Twist, "Exploring the Temporal Dimension in Policy Evaluation Studies”, Policy Sciences, vol. 31, núm. 3, 2013, pp. 319-330.

Carbonell, Miguel, "El derecho de acceso a la información como derecho fundamental”, en S. López-Ayllón (coord.), Democracia, transparencia y Constitución, México, UnAM-IFAI, 2006, pp. 3-18.

Durazo, A., Saldos del cambio, México, Plaza Janés, 2006.

Dussauge, M., "The Neglected Dimension: Bringing Time Back into CrossNational Policy Transfer Studies”, Policy Studies, vol. 33, núm. 6, 2012, pp. 567-585.

Escobedo, J. F., "Movilización de opinión pública en México: el caso del Grupo Oaxaca y la Ley Federal de Acceso a la Información Pública”, Derecho Comparado de la Información, núm. 2, 2003, pp. 63-92.

Falleti, T., "A Sequential Theory of Descentralization: Latin American Cases in Comparative Perspective”, American Political Science Review, vol. 99, núm. 3, 2005, pp. 327-346.

Flores, V., "Políticas públicas en México y la transición moral y pública", en Raúl Béjar Navarro (coord.), Las políticas públicas en la alternancia mexicana, México, unAM, 2004.

Goetz, K., "How Does the EU Tick? Five Propositions on Political Time", Journal of European Public Policy, vol. 16, núm. 2, 2009, pp. 202-220. 
Goetz, K. y J.-H. Meyer-Sahling, "Political Time in the EU: Dimensions, Perspectives, Theories”, Journal of European Public Policy, vol. 16, núm. 2, 2009, pp. 180-201.

Guerrero, E. y L. Ramírez de Alba, "La transparencia en México en el ámbito subnacional: Una evaluación comparada de las leyes estatales”, en S. López Ayllón (ed.), Democracia, transparencia y constitución, México, UNAM-IFAI, 2006.

Helmke, Gretchen y Levitsky, Informal Institutions and Democracy: Lessons from Latin America, Baltimore, Johns Hopkins University Press, 2006.

Jacobs, A., "The Politics of When: Redistribution, Investment and Policy Making for the Long Term”, British Journal of Political Science, vol. 38, núm. 2, 2008, pp. 193-220.

Jordana, J., X. Fernández y D. Levi-Faur, "The Global Diffusion of Regulatory Agencies: Channels of Transfer and Stages of Diffusion", Comparative Political Studies, vol. 44, núm. 10, 2011, pp. 1343-1369.

Linz, J., "Democracy's Time Constraints", International Political Science Review, vol. 19, núm. 1, 1998, pp. 19-37.

López Ayllón, S., "La creación de la Ley de Acceso a la Información en México: una perspectiva desde el Ejecutivo Federal”, en Hugo Concha et al. (coords.), Transparentar al Estado: la experiencia mexicana de acceso a la información, México, UNAM, 2005, pp. 1-38.

Mendel, Toby, Freedom of Information, A Comparative Legal Survey, París, Unesco, 2003.

, Amending Access to Information Legislation: Legal and Political Issues, París, Unesco, 2008.

, The Right to Information in Latin America: A Comparative Legal Survey, Quito, Unesco, 2009, disponible en http://portal.unesco.org/ ci/en/ev.phpURL_ID=28958\&URL_DO=DO_TOPIC\&URL_SECTION=201.html

— RTI Rating Data Analysis Series: Overview of Results and Trends, Canadá-España, CLD-AIE, 2013.

Meyer-Sahling, J.-H., "Time and European Governance: An Inventory", trabajo presentado en la Biennal Conference of the European Studies Association, Montreal, 2007.

Michener, G., "The Surrender of Secrecy”, tesis doctoral, Austin, University of Texas at Austin, 2010. 
, "FOI Laws Around the World", Journal of Democracy, vol. 22, núm. 2, 2011, pp. 145-159.

Neuman, L., Enforcement Models. Content and Context, Washington, World Bank, 2009.

Neumann y R. Calland, "Making the Law Work: The Challenges of Implementation”, en A. Florini (ed.), The Right to Know, Nueva York, Columbia University Press, 2007, pp. 179-213.

Organización de Estados Americanos, Ley Modelo Interamericana sobre Acceso a la Información, 2010.

Page, E., "Future Governance and the Literature on Policy Transfer and Lesson Drawing”, ESRC Future Governance Papers, 2000.

Pierson, P., Politics in Time, Nueva York, Cambridge University Press, 2004.

Pollitt, C., Time, Policy, Management: Governing with the Past, Oxford, Oxford University Press, 2008.

Roberts, A., "Three Patterns in the Diffusion of Transparency Rules: Money, Guns and Human Rights", 2003, disponible en http://papers. ssrn.com/sol3/papers.cfm?abstract_id=1439722, con acceso el 20 de noviembre de 2014.

Rogers, E., Diffusion of Innovations, Nueva York, Free Press, 1995.

Schedler, Andreas y Javier Santiso, "Democracy and Time: An Invitation", International Political Science Review, vol. 19, núm. 1, 1998, pp. 5-18.

Schedler, A., "Authoritarianism's Last Line of Defense", Journal of Democracy, vol. 21, núm. 1, 2010, pp. 69-80.

Schudson, M., "Origins of the Freedom of Information Act in the United States", en N. Bowles et al. (eds.), Transparency in Politics and the Media: Accountability and Open Government, Oxford, I.B. Tauris - Reuters Institute for the Study of Journalism, University of Oxford, 2014.

Villanueva, E., Derecho de acceso a la información pública en Latinoamérica, México, IIJ-unam, 2003.

, Derecho de acceso a la información en el mundo, México, Miguel Ángel Porrúa/IIJ, 2006.

Villanueva, E., P. Gómez y C. Pacheco, Derecho de acceso a la información pública en México: indicadores legales, México, Limac, 2005.

Weyland, K., Bounded Rationality and Policy Diffusion: Social Sector Reform in Latin América, Princeton, Princeton University Press, 2007. 
Bases de datos

Freedom House, Freedom in the World, 2013, disponible en https://freedomhouse.org/report/freedom-world/freedom-world-2013\#. VIko7zGG-So

Marshall, M. y B. Cole, Conflict, governance and state fragility, 2013, disponible en http:/ / www.systemicpeace.org/globalreport.html

Right to Information Index, 2013, disponible en http://rti-rating.org/index.php 


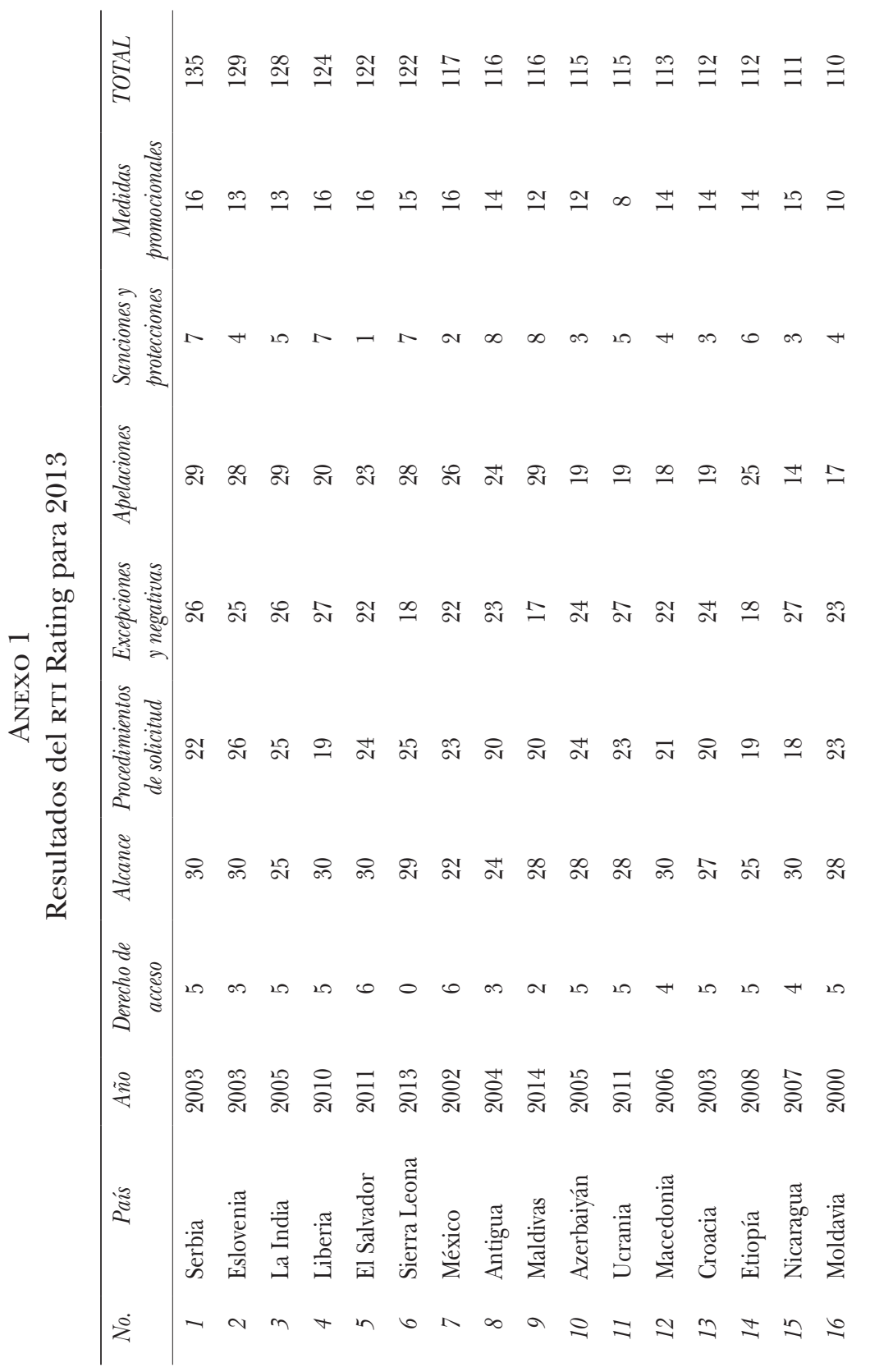




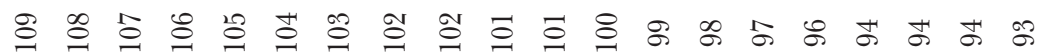
\#교

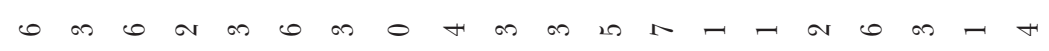
廿 중 สำ สิ

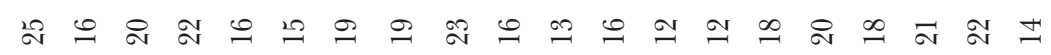
요의 웡요의

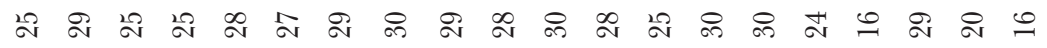

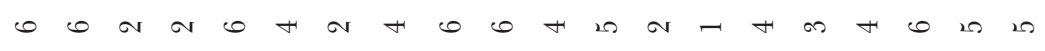

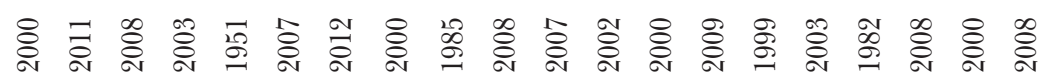

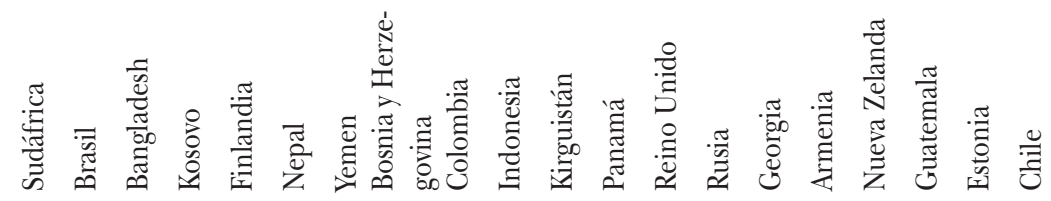

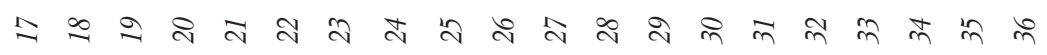




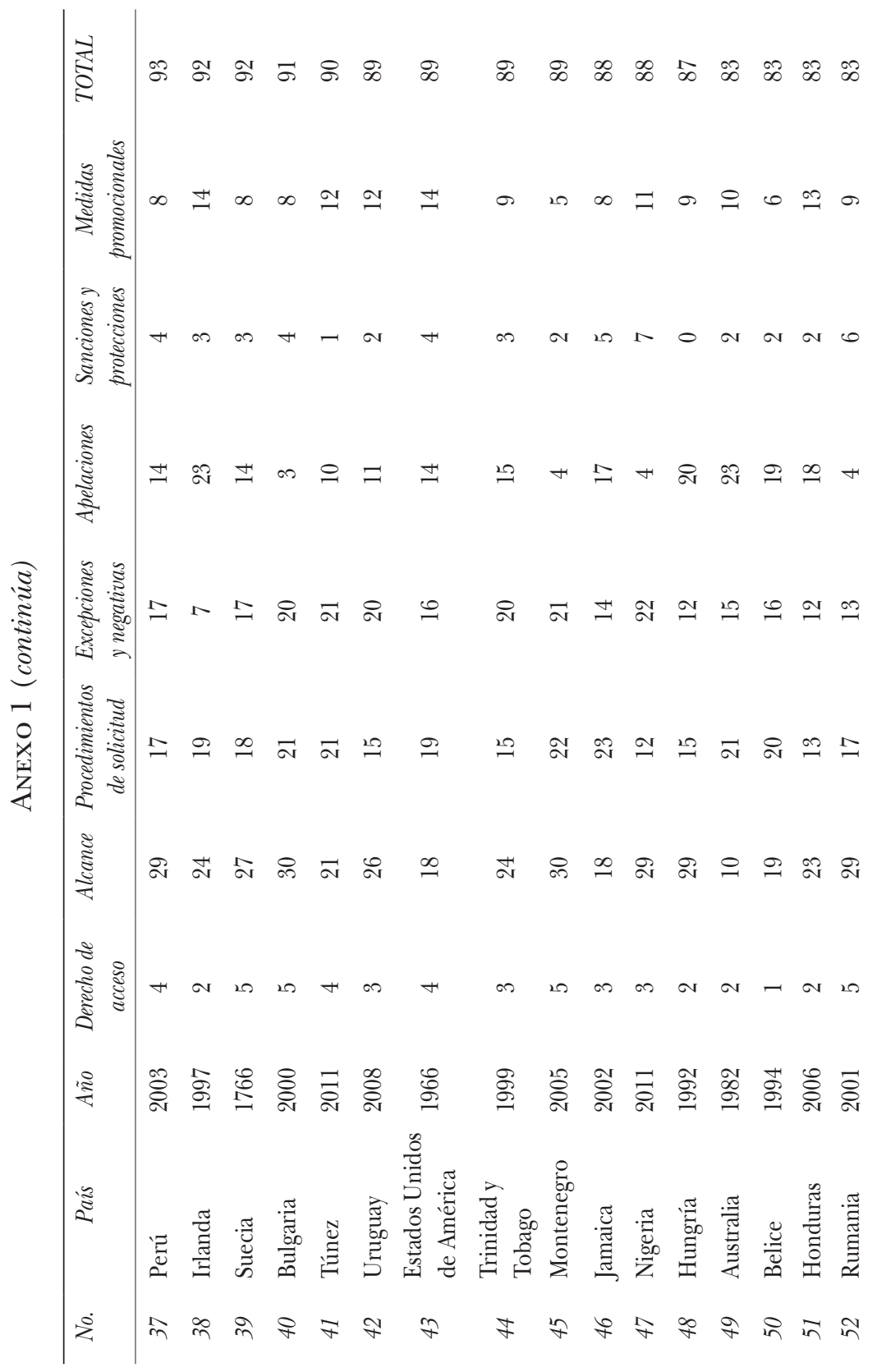


m a $\infty$ h o d t

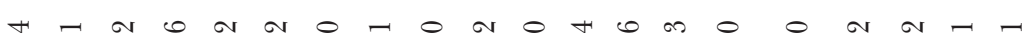

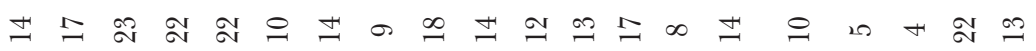
ㅇำ 요묘

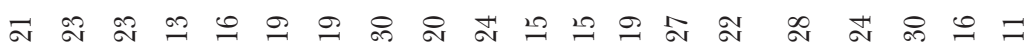

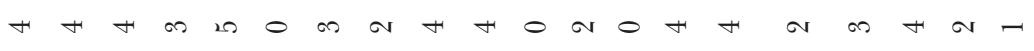

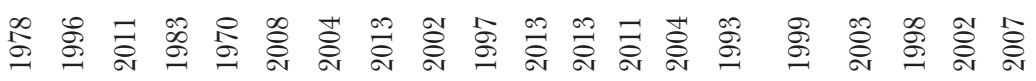

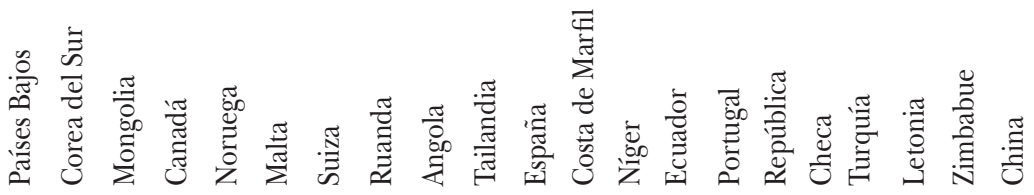

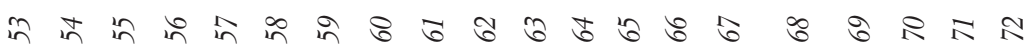




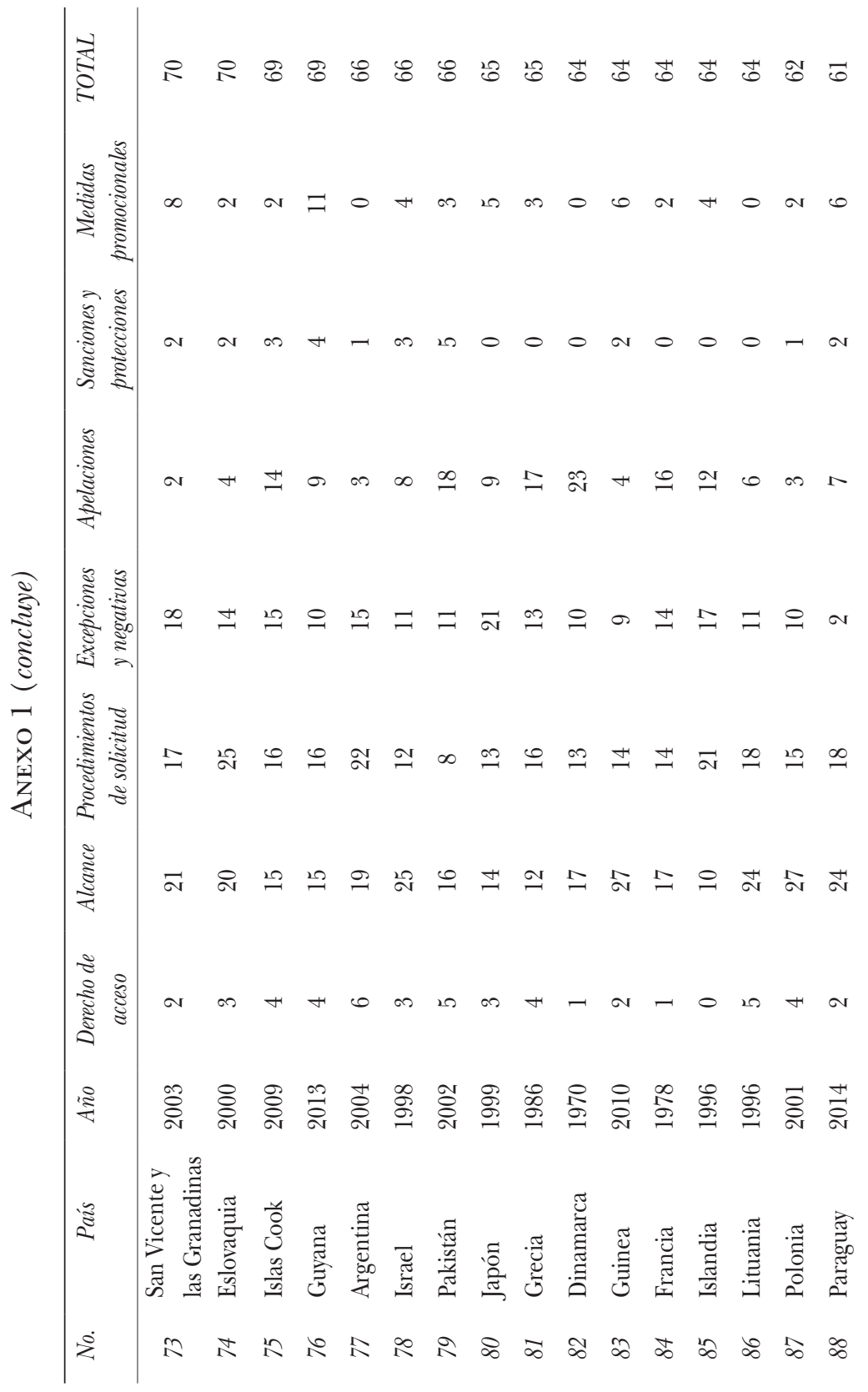




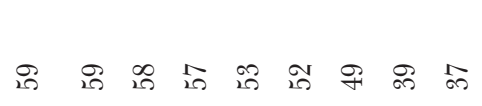

$$
\begin{aligned}
& \text { a o a n n o a ho } \\
& a \text { a h o o o a } 0
\end{aligned}
$$

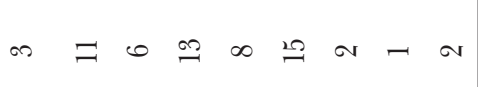

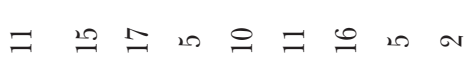

$$
\begin{aligned}
& \text { H }
\end{aligned}
$$

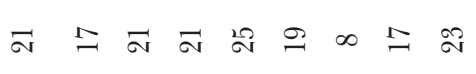

$$
\begin{aligned}
& \text { so a a a b o ho a } \\
& \text { 苍 }
\end{aligned}
$$

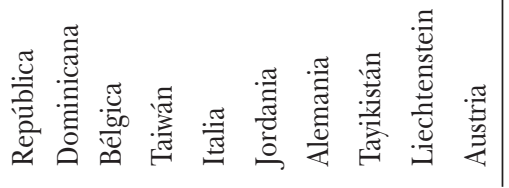

$$
\begin{aligned}
& \text { के ๙ } \nwarrow \text { ๙ }
\end{aligned}
$$

